\title{
Ação do fator de crescimento de fibroblasto básico na cicatrização da aponeurose abdominal de $\operatorname{ratos}^{1}$
}

\author{
Aldo da Cunha Medeiros ${ }^{2}$ \\ Antônio Medeiros Dantas Filho ${ }^{3}$ \\ Keyla Ferreira Borges da Rocha ${ }^{4}$ \\ Ítalo Medeiros de Azevêdo ${ }^{5}$ \\ Francisca Yane Bulcão de Macedo ${ }^{6}$
}

\begin{abstract}
Medeiros AC, Dantas Filho AM, Rocha KFB, Azevêdo IM, Macêdo FYB. Ação do fator de crescimento de fibroblasto básico na cicatrização da aponeurose abdominal de ratos. Acta Cir Bras [online] 2003 vol 18 suppl 1. Disponível em www.scielo.br/acb.
\end{abstract}

RESUMO: Objetivo: Trabalho realizado em ratos com o objetivo de estudar o efeito do Fator de Crescimento de Fibroblastos básico ( $\mathrm{FCFb}$ ) na cicatrização da aponeurose abdominal. Métodos: Foram usados 20 ratos Wistar separados aleatoriamente em 2 grupos iguais. Os animais foram anestesiados com pentobarbital sódico na dose de $20 \mathrm{mg} / \mathrm{Kg}$ por via intraperitoneal e submetidos a laparotomia mediana de $4 \mathrm{~cm}$, cuja camada aponeurótica foi suturada com mononylon 5- 0 . No grupo I foi aplicada a dose de $5 \mathrm{mg}$ de FCFb sobre a sutura da aponeurose. No grupo II (controle) foi aplicada solução salina $0,9 \%$ sobre a linha se sutura. Após observação por 7 dias os animais foram mortos com superdose de anestésico. A camada aponeurótica com 1,5 cm de largura foi submetida a teste de resistência à tensão empregando a Máquina de Ensaios EMIC MF500. Biópsias das zonas de sutura foram processadas e coradas com HE e o tricômico de Masson. Os achados histopatológicos foram quantificados através de sistema digital (Image pro-plus) de captura e processamento de imagens. Os dados obtidos foram analisados pelo teste $\mathrm{T}$ com significância 0,05. Resultados: Nos animais do grupo I (experimental) a zona de sutura da camada aponeurótica suportou a carga de $1.103 \pm 103,39 \mathrm{gf}$. A quantificação dos dados histopatológicos desse grupo atingiu a densidade média $226 \pm 29,32$. No grupo II (controle) a carga suportada pela zona de sutura foi de 791,1 $\pm 92,77$ gf. Quando foram comparadas as médias das resistências à tensão dos dois grupos, observou-se uma diferença significante $(\mathrm{p}<0,01)$. $\mathrm{O}$ exame histopatológico das lâminas desse grupo relevou densidade média $114,1 \pm 17,01$, correspondendo a uma diferença significante quando comparadas as médias dos dois grupos $(\mathrm{p}<0,01)$. Conclusão: Os dados permitem concluir que o $\mathrm{FCFb}$ contribuiu para aumentar a resistência da aponeurose suturada e para melhorar os parâmetros histopatológicos da cicatrização.

DESCRITORES: Fator de crescimento de fibroblastos. Cicatrização. Aponeurose abdominal.

1. Trabalho do Núcleo de Cirurgia Experimental-UFRN. Apoiado pelo CNPq

2. Professor Adjunto, Doutor em Cirurgia, Chefe do Núcleo de Cirurgia Experimental e da Disciplina de Técnica Operatória-UFRN; Pesquisador nível I do CNPq.

3. Mestre em Cirurgia, Professor Assistente do Departamento de Cirurgia-UFRN. Aluno do Programa de Pós-graduação-Doutorado.

4. Professora Mestre do Departamento de Patologia-UFRN.

5. Aluno do Departamento de Estatística-UFRN

6. Aluna bolsista de Iniciação Científica PIBIC-CNPq 


\section{INTRODUÇÃO}

A musculatura abdominal ântero-lateral é composta pelo músculo reto do abdome e três ânterolaterais. As forças desenvolvidas pelos músculos do abdome, dispostas em vários sentidos, têm como resultante uma força que tende a afastar a linha mediana. Essas forças em equilíbrio exercem tensão considerável durante os esforços abdominais sobre a linha alba, formada pelo entrecruzamento de fibras das aponeuroses dos músculos oblíquos e transverso. A disposição desses músculos e aponeuroses, tanto no homem quanto nos animais, contribui para dar sustentação às vísceras abdominais, de modo que a reconstituição da parede do abdome ao término das operações é de grande importância, dado o grande número de complicações que podem surgir. Uma delas, a mais freqüente, é a hérnia incisional, a única hérnia da parede abdominal realmente iatrogênica ${ }^{1}$.

O fator de crescimento de fibroblasto básico $(\mathrm{FCFb})$ é uma proteína de 17.000 DA de peso molecular que tem funcionado como potente fator angiogênico ${ }^{2}$, sendo mitogênico e quimiotático para fibroblastos e células endoteliais ${ }^{3}$. $\mathrm{O}(\mathrm{FCFb})$ infiltrado em feridas incisionais no terceiro dia pós-operatório acelerou o ganho da resistência em $35 \%$ entre o quinto e sétimo dias de observação ${ }^{4}$.

O presente trabalho tem o objetivo de estudar a ação do FCFb na cicatrização da aponeurose abdominal de ratos, com a finalidade de procurar meio que fortaleça a ferida operatória praticada nesta estrutura anatômica, sujeita a tensão considerável no pós-operatório.

\section{MÉTODOS}

Foram operados 20 ratos Wistar, separados aleatoriamente em grupo I $(n=10)$ e grupo II $(n=10)$. Todos os animais foram mantidos em gaiolas individuais, com oferta de água e alimento Labina PurinaÒ ad libitum e receberam apenas dieta líquida no pré-operatório por um período de 12 horas. Os animais foram anestesiados com pentobarbital sódico na dose de $20 \mathrm{mg} / \mathrm{Kg}$ por via intraperitoneal. Após depilação e anti-sepsia da parede abdominal com povidona, foram submetidos a uma laparotomia mediana de $4 \mathrm{~cm}$ a partir do apêndice xifóide. Em seguida, foi fechada a camada aponeurótica com fio de mononylon número 5-0. Nos animais do grupo I (experimental) foi aplicada sobre a linha de sutura a dose de $5 \mathrm{mg}$ de fator de $\mathrm{FCFb}$ (procedência SIGMAâ) em colágeno solúvel, como veículo, constituindo uma preparação viscosa e aderente segundo a técnica utilizada por Slavin et $\mathrm{al}^{5}$. Em seguida, foi suturada a pele com o mesmo fio. Nos animais do grupo II (controle) foi aplicado o mesmo volume de solução salina $0,9 \%$ sobre a linha se sutura. Após 7 dias de observação os animais foram mortos com superdose de anestésico. Em seguida, a camada musculoaponeurótica foi ressecada em formado em ampulheta, de modo que a região da sutura tivesse $1,5 \mathrm{~cm}$ de largura e as extremidades da peça $3 \mathrm{~cm}$ de cada lado. A peça assim preparada foi presa a duas garras especiais sob pressão e levada para teste de resistência à tensão empregando a Máquina de Ensaios EMIC MF500. O teste foi feito utilizando-se gf (grama força) como unidade, e o estirando-se a peça a uma velocidade constante de $20 \mathrm{~cm} /$ min. Em seguida foi feita biópsia da zona de sutura que foi fixada em formol a $10 \%$ por $48 \mathrm{hs}$, cujos cortes foram tratados com técnica de rotina e corados com hematoxicilina-eosina e o tricômio de Masson. A análise quantitativa foi feita através de microscopia óptica, num microscópio Olympus ${ }^{\hat{a}}$ modelo BX50, utilizando-se o aumento de $200 \mathrm{x}$, sendo as imagens captadas através de câmera digital, e enviadas ao computador para estudo da densidade dos componentes histológicos da cicatrização, através do programa Image Pro Plus ${ }^{a}$, versão 4.0 para Windows ${ }^{\hat{a}}$. O aporte de fibras colágenas, de células inflamatórias inerentes ao processo cicatricial, e a formação de neovasos, foram quantificados em unidades de densidade média.. Os dados obtidos foram analisados pelo teste $\mathrm{T}$ de Student com significância 0,05 e os resultados expressos em média \pm desvio padrão.

\section{RESULTADOS}

Os animais suportaram sem complicações o período de observação. No grupo I (experimental) a zona de sutura da camada musculoaponeurótica suportou a carga de $1.103 \pm 103,39 \mathrm{gf}$. Os valores discriminados encontram resumidos na tabela 1. A quantificação dos dados histopatológicos desse grupo atingiu o escore $226 \pm 29,32$ pontos (tabela 2). Chamou a atenção a exuberância do número de macrófagos e fibroblastos nas lâminas examinadas, o grande número de neovasos, bem como a quantidade de fibras de colágeno, especialmente evidenciadas pelo tricrômico de Masson.

No grupo II (controle) a carga suportada pela zona de sutura atingiu a média de 791,1 $\pm 92,77$ gf. Quando foram comparadas as médias das resistências à tensão dos dois grupos, observou-se uma diferença significante $(\mathrm{p}<0,01)$. O exame histopatológico das lâminas desse grupo relevou escore de 114,1 $\pm 17,01$ pontos, correspondendo a uma diferença significante $(\mathrm{p}<0,01)$ quando comparadas as médias dos dois grupos (tabela 2). 
Tabela 1 - Valores da resistência da aponeurose à tensão dos dois grupos estudados, após sete dias de observação (Valores em grama força gf)

\begin{tabular}{c|c|c}
\hline${\text { Ratos } \mathrm{n}^{\circ}}^{-}$ & Grupo I (FCF) & Grupo II (Controle) \\
\hline 1 & 1123 & 846 \\
\hline 2 & 1077 & 723 \\
\hline 3 & 1075 & 771 \\
\hline 4 & 1217 & 955 \\
\hline 5 & 1254 & 681 \\
\hline 6 & 985 & 765 \\
\hline 7 & 1204 & 877 \\
\hline 8 & 1010 & 880 \\
\hline 9 & 948 & 698 \\
\hline 10 & 1145 & 715 \\
\hline Média \pm D. padrão & $1103,8 \pm 103,39$ & $791,1 \pm 92,77$ \\
\hline
\end{tabular}

Diferença entre os dois grupo estatisticamente significante $(p<0,01)$.

Tabela 2- Densidade média dos elementos histopatológicos observados nos dois grupos de acordo com a quantificação utilizada.

\begin{tabular}{c|c|c}
\hline Ratos $^{\circ}$ & Grupo I (FCF) & Grupo II (Controle) \\
\hline 1 & 245 & 98 \\
2 & 221 & 125 \\
3 & 241 & 112 \\
4 & 192 & 131 \\
5 & 254 & 122 \\
6 & 178 & 90 \\
7 & 192 & 89 \\
8 & 238 & 134 \\
9 & 264 & 110 \\
10 & 238 & 130 \\
\hline Média \pm D. padrão & $226,3 \pm 29,32$ & $114,1 \pm 17,01$ \\
\hline
\end{tabular}

As diferenças entre as médias são estatisticamente significantes $(\mathrm{p}<0,01)$

\section{DISCUSSÃO}

A cicatrização normal da ferida operatória requer uma interligação complexa e ordenada de vários mediadores bioquímicos e celulares. A aplicação da tecnologia de recombinação e de purificação bioquímica do DNA, através de técnica de cromatografia de afinidade pela heparina, permitiu a identificação de vários fatores de crescimento. A técnica da reação e ampliação da cadeia da polimerase apontou a origem celular desses fatores ${ }^{6,7}$.
Atualmente sabe-se que os fatores de crescimento exercem funções importantes como: são angiogênicos, quimiotáticos, indutores ou inibidores da diferenciação celular, transformação ou indução da síntese de proteínas e são mais adequadamente descritos como cito$\operatorname{cinas}^{8}$.

Dentre os fatores de crescimento, os que parecem ter mais destaque na cicatrização das feridas são os fatores de crescimento de fibroblastos (FCF). Há dois 
tipos de FCF, sendo um de reação básica e outro de reação ácida, de acordo com o potencial isoelétrico. Destes o FCF de reação básica (FCF-b) exerce um maior número de reações fisiológicas ${ }^{9}$. Os fatores de crescimento são essencialmente angiogênicos, promovem, portanto, o crescimento vascular, aspecto muito desejável nos processos de cicatrização. Além disso, sua ação é indireta na síntese de colágeno, proteína que dá resistência às feridas em cicatrização ${ }^{10}$.

Estudo experimental realizado para observar a vascularização da aponeurose abdominal mostrou que há vasos em quantidade muito limitada na intimidade desse tecido, caracterizando uma estrutura anatômica de nutrição precária ${ }^{11}$. A escolha da aponeurose abdominal para estudo deveu-se a suas características de estrutura mal vascularizada que conseqüentemente é de cicatrização lenta, é submetida a grandes esforços e tensões e freqüentemente lesada nas vias de acesso ao abdome. A metodologia da determinação da resistência da aponeurose à tensão foi testada de várias maneiras em outros estudos, todos com resultados satisfató$\operatorname{rios}^{12,13,14}$. O exame histopatológico qualitativo e quantitativo realizado com equipamento de captação de imagem e tratamento digital contribuiu para eliminar o fator subjetivo da avaliação pelo patologista. Alguma outras técnica têm sido utilizadas ${ }^{15,16,17,18}$.

Mcgee et $\mathrm{al}^{4}$ que assinalaram a ação do $\mathrm{FCFb}$ na epitelização mais rápida, a intensa neovascularização e a deposição do colágeno na matriz extracelular, mesmo na presença de infecção. Tem sido demonstradas as suas funções proliferativas e angiogênicas, e ficou provado que os mesmos só têm ação local não tendo repercussões renais, eletrolíticas e hematológicas ${ }^{4}$. No campo da oftalmologia, Mazue et $\mathrm{al}^{19}$ demonstraram o aumento da celularidade, da angiogênese e da maturação do colágeno. Resultados semelhantes aos encontrados no presente trabalho forma encontrados em estudos experimentais recentes ${ }^{20,21}$.

No presente estudo concluiu-se que o FCF-b contribuiu para aumentar a resistência da aponeurose à tensão, melhorando sobremaneira a evolução histopatológica do processo cicatricial, o que fez com que a ferida operatória pudesse se tornar menos susceptível à ruptura.

\section{REFERÊNCIAS}

1. Ellis H, Bucknall TE, Cox PJ. Abdominal incisions and their closure. Curr Probl Surg 1985; 22: 1-51.

2. Folkman J, Klägsbrun M. Angiogenic factors. Science 1987; 235: 442-447.

3. Terranova VP, Diflorio R, Lyall RM, Hic S, Fressal R, Macaig T. Human endotelial cells are chemotactic to endothelial cell growth factor and heparin. J Cell Biol 1985;101:2330-4.
4. McGee G, Davidson J, Buckley A. Recombinant basic fibroblast growth factor accelerates wound healing. J Surg Res 1988; 45 : 145-153.

5. Slavin J, Nash JR, Kingsnorth NA. Effect of transforming growth factor beta and basic fibroblast growth factor on steroidimpaired healing intestinal wounds. Br J Surg 1992; 79: 69-72.

6. Fiddes J, Hebda P, et al. Preclinical wound-healing studies with recombinant human basic fibroblast growth factor. Ann N Y Acad Sci 1991; 638: 316-328.

7. Scheigerer L. Basic fibroblast growth factor as a wound healing hormone. Trends Pharmacol Sci 1988; 9: 427-428.

8. Gospodarowicz D, Ferrara N. Structural characterization and biological function of fibroblast growth factor. Endocr Rev 1987; 8: 95-114.

9. Klagsbrun M, Baird A. A dual receptor system is required for fibroblast growth factor activity. Cell 1991; 67:229-231.

10. Knighton D, Philips G, Fiedel V. Wound healing angiogenesis: indirect stimulation by basic fibroblast growth factor. J Trauma 1990; 30:s1134-s144

11. Medeiros AC, Barreto H, Garcia OS. Vascularização dos tendões planos do abdome. Estudo experimental. Rev Col Bras Cir 1981; 8: 274-277.

12. MaranhãoRFA, Baroni B, Giudici R. Estudo comparativo entre as anastomoses ileocólica termino-terminal e término-lateral em cães. Acta Cir Bras 1987;2:73-81.

13. Westphalen ACA, Cunha MEP, Camargo PV, Silva RC, Teruchkin M, Edelweiss MIA, Gomes C. Tendão x cicatrização. Retomada da resistência. Acta Cir Bras. 1995;10:169-172.

14. Tognini JRF, Goldenberg S, Naresse LE, Simões MJ, Alves FLG, Magalhães AM. Estudo comparativo entre a sutura contínua e a com pontos separados na aponeurose abdominal de ratos. Acta Cir Bras 1997;12:249-254.

15. Fatureto, MC, Simões MJ, Teixeira VPA, Goldenberg S. Aspectos morfológicos e morfométricos do processo inflamatório provocado por fios de catgut simples no subcutâneo de ratos tratados com diclofenaco sódico. Acta Cir Bras 1989;4:5-9

16. Campos H, Ferreira LM, Santos WLC, Araújo MCM. Efeitos da nicotina nos retalhos cutâneos em ratos. Acta Cir Bras 2001;16:206-210

17. Falcão SC, Lopes SL, Coelho ARB, Almeida EL. Pele de Rana catesbeiana no tratamento de feridas cutâneas produzidas em cães. Alterações macroscópicas e microscópicas resultantes da interação desses tecidos. Estudo preliminar. Acta Cir Bras 2002;17:151-159.

18. Biondo-Simões MLP, Collaço LM, Veronese C, RibasMM, Flores SR. Behavior of chromed catgut and polyglecaprone 25 sutures in the urinary bladder of rats, with special reference to stone formation. Acta Cir Bras 1998;13:26-29.

19. Mazue G, Bertolero F, Jacob C. Preclinical and clinical studies with recombinant human basic fibroblast growth factor. Ann N Y Acad Sci 1991; 638: 329-340.

20. Ono I. The effects of basic fibroblasts growth factor on the breaking strength of acute incisional wounds. J Dermatol Sci 2002;29:104-113.

21. Iwakura A, Tabata Y, Tamura N, doi K, Nishimura K, Nakamura T, Shimizu Y, Fujita M, Komeda M. Gelatin sheet incorporating basic fibroblast growth factor enhances healing of devascularized sternum in diabetic rats. Circulation 2001;104(12 suppl 1): 325-329. 
Medeiros AC, Dantas Filho AM, Rocha KFB, Azevêdo IM, Macêdo FYB. Use of basic fibroblast growth factor in the healing of abdominal aponeurosis in rats. Acta Cir Bras [online] 2003 vol 18 suppl 1. Available in www.scielo.br/acb.

ABSTRACT: Objective: As little is known about the use of basic Fibroblast Growth Factor $(\mathrm{FCFb})$ in the healing of abdominal aponeurosis, an experimental work was done to study it. Methods: Twenty Wistar rats randomly separated in two groups were used. They were anesthetised with pentobarbital $20 \mathrm{mg} / \mathrm{Kg}$ intraperitonealy, submited to a $4 \mathrm{~cm}$ median laparotomy and the aponeurosis was sutured with nylon 5-0. In group I $5 \mathrm{mg}$ of $\mathrm{FCFb}$ was applied over the sutured aponeurosis end the group II received saline $0,9 \%$ over it. After seven days the rats were killed by an overdose of anesthetic. A transversal $1,5 \mathrm{~cm}$ wideness sample of aponeurosis was submited to tensil strenght test, using the assay device EMIC MF500. Biopsies from the sutured tissue were processed and colored by HE and Masson trichromic. The histopatologic data were quantitated and transformed into mean density by the digital equipment Image Pro-plus. The Student $t$ test was used and the differences were significant when $p<0,05$. Results: In group I the the mean tensil strength was $1.103 \pm 103,39 \mathrm{gf}$ and the mean density of histopatologic data was $226 \pm 29,32$. In group II (control) the tensil strenght was $791,1 \pm 92,77 \mathrm{gf}$ and the histolopatogical density was $114,1 \pm 17,01$. The differences were statisticaly significant $(p<0,01)$. Conclusion: In conclusion, our data show that FCFb induces an increase of tensil strenght of sutured aponeurosis of rats and turns better the histopatological parameters of wound healing.

KEY WORDS: Fibroblast Growth Factor. Healing. Abdominal aponeurosis

Correspondência:

Av. Miguel Alcides Araújo 1889

59078-270 Natal -RN 